\title{
Do Patient Race and Sex Change Surgeon Recommendations for TKA?
}

\author{
Christopher J. Dy MD, MPH, Stephen Lyman PhD, Carla Boutin-Foster MD, MPH, \\ Karla Felix PhD, Yoon Kang MD, Michael L. Parks MD
}

Received: 9 April 2014/ Accepted: 6 October 2014/Published online: 22 October 2014

(C) The Association of Bone and Joint Surgeons \& 2014

\begin{abstract}
Background Prior investigations have suggested that physician-related factors may contribute to differential use of TKA among women and ethnic minorities. We sought to evaluate the effect of surgeon bias on recommendations for TKA.
\end{abstract}

Funding was received from National Institute of Arthritis and Musculoskeletal and Skin Diseases (NIAMS) grant T32-AR07281 (CJD) and the Hospital for Special Surgery's Eduardo Salvati Research Grant (CJD). Each author certifies that he or she has no commercial associations (eg, consultancies, stock ownership, equity interest, patent/licensing arrangements, etc) that might pose a conflict of interest in connection with the submitted article.

All ICMJE Conflict of Interest Forms for authors and Clinical Orthopaedics and Related Research editors and board members are on file with the publication and can be viewed on request.

Each author certifies that his or her institution approved or waived approval for the human protocol for this investigation and that all investigations were conducted in conformity with ethical principles of research.

This study was performed at the Hospital for Special Surgery and Weill Cornell Medical College, New York, NY.

\section{J. Dy, K. Felix, M. L. Parks}

Department of Orthopaedic Surgery, Hospital for Special Surgery, New York, NY, USA

\section{J. Dy, S. Lyman}

Healthcare Research Institute, Hospital for Special Surgery, New York, NY, USA

\section{J. Dy $(\square)$}

Department of Orthopaedic Surgery, Washington University School of Medicine, 660 S. Euclid Ave, Campus Box 8233, St. Louis, MO 63124, USA

e-mail: dyc@wudosis.wustl.edu; christopherjdy@gmail.com

C. Boutin-Foster, Y. Kang

Department of Medicine, Weill Cornell Medical College,

New York, NY, USA
Questions/purpose Using an experimental approach with standardized patient scenarios, we sought to evaluate surgeon recommendations regarding TKA, specifically to determine whether recommendations for TKA are influenced by (1) patient race, and (2) patient sex.

Methods We developed four computerized scenarios for all combinations of race (white or black) and sex (male or female) for otherwise similar patients with end-stage knee osteoarthritis. Patients gave an orthopaedic history of 2 years worsening pain with decreased functional status and failure of oral antiinflammatory medications and corticosteroid intraarticular injections. Orthopaedic surgeons attending the 2012 annual meetings of the New York State Society of Orthopaedic Surgeons and American Association of Hip and Knee Surgeons were recruited for the study. Surgeons passing an open recruitment table at each meeting were asked to participate. Of the 1111 surgeons in attendance at either meeting, 113 (10.2\%) participated in the study. All participants viewed the "control" patient's story (white male) and were randomized to view one of the three "experimental" scenarios (white female, black male, black female). After viewing each scenario, the participants were anonymously asked whether they would recommend TKA. An a priori power analysis showed that 112 participants were needed to detect a $15 \%$ difference in the likelihood of recommending surgery for white versus nonwhite patients in the test scenarios evaluated with $90 \%$ power at a level of significance of 0.05 .

Results Of the 39 surgeons who viewed the white male plus black female scenario, there were $33(85 \%)$ concordant responses (TKA offered to both patients) and six discordant responses (TKA offered to only one of the patients), with no effect of patient race and $\operatorname{sex}(\mathrm{p}=0.99)$. Of the 37 surgeons who viewed the white male plus black 
male scenario, there were $33(89 \%)$ concordant responses and four discordant responses, with no effect of patient race ( $\mathrm{p}=0.32$ ). Of the 37 surgeons who viewed the white male plus white female scenario, there were 30 (77\%) concordant responses and seven discordant responses, with no effect of patient sex $(\mathrm{p}=0.71)$.

Conclusion After orthopaedic surgeons viewed video scenarios of patients with end-stage knee osteoarthritis, patient race and sex were not associated with a different likelihood of a surgical recommendation. Our findings support the notion that patient race and sex may be less influential on decision making when there are strong clinical data to support a decision. Physician bias may have a greater effect on decision making in situations where the indications for surgery are less clear.

\section{Introduction}

Although the use of total joint arthroplasties is increasing $[26,28,29]$, there is a difference in use in women and ethnic minorities (black and Hispanic) compared with white men [4, 5, 8, 14, 20, 37]. These disparities may persist after adjusting for socioeconomic status, insurance coverage, and general health status [17, 24, 37]. In accordance with initiatives $[6,40]$, increased attention has been focused on reducing disparity in the use of total joint arthroplasties among minority populations.

Numerous studies have investigated the patient-specific characteristics that may contribute to underuse of total joint arthroplasties, including decreased familiarity with the procedure, lower expectations for surgical outcomes, and overall uncertainty regarding surgical intervention among minorities [9, 16, 18, 21, 22]. An overall recommendation from these studies is that physician-related factors, such as practice tendencies and personal biases (conscious and unconscious), may contribute to disparities in arthritis care and need to be evaluated further [5, 35]. While Wright et al. [42] and Borkhoff et al. [4] evaluated the effect of patient sex on recommendations for total joint arthroplasy, the influence of patient race on decision making for total joint arthroplasties has not been experimentally evaluated. However, the existing body of experimental evidence suggests that physician bias regarding patient race influences treatment recommendations for acute coronary syndrome, peripheral vascular disease, and breast cancer [1, 12, 25, 36]. Without additional investigation to understand the potential influence of physician bias, the development of strategies to eliminate disparities is hindered.

In the current investigation, we therefore used an experimental approach to evaluate surgeon recommendations for TKA. We asked the following research questions:
(1) Are recommendations for TKA influenced by patient race? (2) Are recommendations for TKA influenced by patient sex? We hypothesized that black and female patients would be less likely to receive recommendations for surgery compared with white and male patients.

\section{Materials and Methods}

\section{Study Design}

\section{Computerized Survey Instrument}

A computerized survey instrument, consisting of two video case vignettes and a series of questions, was developed for evaluation of a patient with end-stage osteoarthritis of the knee. After viewing each patient scenario, the participants were anonymously asked whether they would recommend TKA for the patient. Four computerized scenarios were constructed for all combinations of race (white or black) and sex (male or female). Although different actors were used to portray each patient, the patients were identical in every other aspect, including age (68 years old), clothing style, and body habitus (Fig. 1).

The clinical content of the vignette was developed in collaboration with our medical school's clinical skills center. The patient's initial presentation (referred by the primary care physician for evaluation of knee pain) and clinical history (details below) were incorporated in the script. Before filming, the script was reviewed by four arthroplasty surgeons from our institution to ensure its accuracy in portraying a patient who most likely would benefit from TKA. These surgeons had no additional involvement in the study. The dialogue and nonverbal expressions were scripted to be highly similar for each patient portrayed, and the interviews were recorded in one studio using the same camera position. The director of the clinical skills center trained the actors and worked with the audiovisual staff to ensure consistency and quality of the video vignettes.

Subjects were shown a brief synopsis of the patient's medical history (nonsmoker, hypertension or dyslipidemia controlled by a single medication, no surgical history) before the video interview. To minimize the potential influence of socioeconomic status on treatment recommendations, the recorded interview also was preceded by text describing the patient's occupation (retired office manager), education (college graduate), and insurance status (Medicare with supplemental Blue Cross/Blue Shield coverage). The relevant orthopaedic history (constant pain during the past 2 years that is worsened with walking short distances; difficulty with negotiating stairs; failure of oral antiinflammatory medication and two prior corticosteroid 

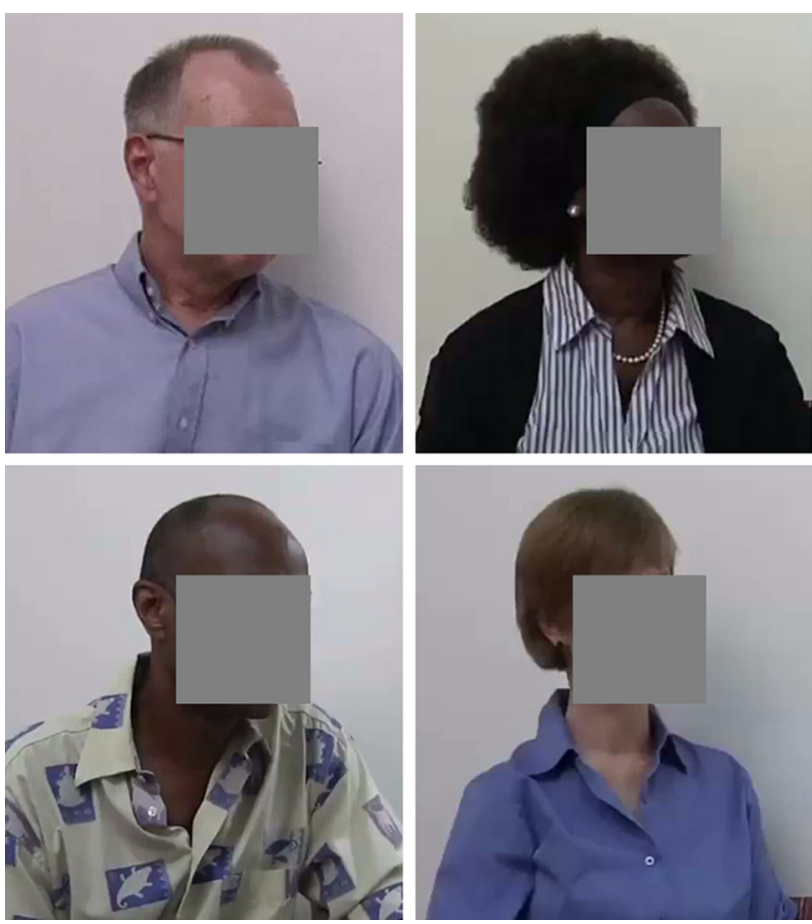

Fig. 1 All actors in the video vignettes portrayed 68 -year old patients with severe knee arthritis that interfered with their desired daily activities. The patients are all retired college graduates who have Medicare with supplemental private insurance coverage.

intraarticular injections) was conveyed by the actor through an interview with an off-screen physician. These history elements were altered slightly for the experimental case scenarios to avoid overt repetition. The video vignette was followed by a text slide describing the patient's physical examination findings (ROM $5^{\circ}-90^{\circ}$ with palpable crepitus, no coronal plane malalignment, intact vascular and neurologic examinations distally). We intentionally chose a straightforward clinical scenario indicating clear appropriateness of TKA to isolate the effect of surgeon bias rather than potentially cloud the interpretation with variations in individual surgeon indications.

After viewing the case presentation, the participating surgeons completed a brief electronic survey modeled after the investigation by Schulman et al. [36] in which subjects were first asked "Assuming that you are comfortable with the procedure and its postoperative care, would you recommend a total knee replacement for this patient?" The response options were "definitely not recommend", "probably not recommend", "probably recommend", and "definitely recommend".

The subjects also were asked to provide their age, sex, ethnicity (Caucasian, African American, Hispanic or Latino, Asian, or Other), number of years in practice, board-certification status, type of practice, any fellowship training in arthroplasty, and estimated number of THAs or TKAs performed annually. These questions were asked anonymously and in a method consistent with the
American Academy of Orthopaedic Surgeons' Orthopaedic Practice in the United States survey [2]. The computerized survey instrument was pilot tested with nine orthopaedic surgery residents at our institution before being administered to research subjects.

\section{Eligibility Criteria}

Orthopaedic surgeons in full-time clinical practice who attended the 2012 New York State Society of Orthopaedic Surgeons (NYSSOS) Annual Meeting and the 2012 American Association of Hip and Knee Surgeons (AAHKS) Annual Meeting were recruited to participate in the study. Potential subjects were excluded if they were in part-time or nonsurgical orthopaedic practice or were currently enrolled in a residency or fellowship training program. Those who attended the meeting were invited by researchers, between conference sessions, to participate in a study on clinical decision making, with the incentive of a $\$ 25$ gift card to a national coffee store. The $\$ 25$ amount is based on the wage-payment model in which the participants will be compensated for their time at a rate appropriate for a professional worker.

\section{Recruitment and Randomization}

The computerized survey instruments were located on four password-protected computers in the Main Exhibit Hall of the conferences. Eligible meeting attendees were asked to participate by a nonphysician member of the research team with the following dialogue:

"Good morning/afternoon. We are conducting a research study on clinical decision making among orthopaedic surgeons. We are offering a \$25 Starbucks Coffee gift certificate in exchange for your completion of a survey after watching two short video clips. The study takes less than 10 minutes to complete. Would you like to participate?"

Conference attendees who chose to participate were led to an audiovisual computer booth. Participants were given the opportunity to ask questions of the nonphysician research staff member throughout the survey process. The computer-based survey was completely anonymous. After completion of the survey, the participant received the $\$ 25$ gift card. None of the physician participants was informed that they would be participating in a study on the effect of race and sex on treatment recommendations to minimize response bias. We did not attempt to ascertain whether the participants were able to deduce the purpose of the study.

Surgeons passing an open recruitment table at each meeting were asked to participate. Of the 1111 surgeons in 
attendance at either meeting, $113(10.2 \%)$ participated in the study. Not all surgeons were approached for participation so it is unknown how many were aware of the study, but decided not to participate.

All study participants viewed the control case of a white male patient and were randomized to view one of the other three experimental scenarios (white female, black male, black female) using block randomization to maintain a balanced number of participants assigned to each scenario. The white male scenario was used as an internal control given that surgeon decision making is widely variable [39]. A block size of three was used, with 24 possible permutations of the scenario sequences created by a computerized randomization generator. The on-site research manager selected one of these arrangements from a randomization scheme list.

The study protocol was reviewed by our institutional review board and was deemed exempt from further review. The research committee of the American Association of Hip and Knee Surgeons and the leadership of the New York State Society of Orthopaedic Surgeons provided advance permission for survey administration during their annual meetings. Neither organization had any additional involvement in subject recruitment, study enrollment, data analysis, or interpretation of the study results.

\section{Participant Demographics}

The survey was completed by 113 respondents (22 at NYSSOS; 91 at AAHKS). The majority of the respondents were male (107/113; 95\%), board certified (107/113; 95\%), and in practice more than 10 years $(79 / 113 ; 72 \%)$ (Table 1). The most common self-reported ethnicity was Caucasian $(96 / 113 ; 83 \%)$, Hispanic/Latino or Asian (4/113; 4\%), African American (3/113; 3\%), other (9/113; $8 \%)$, or no response $(1 / 113)$. More than $1 / 2$ of the respondents were fellowship trained in arthroplasty (67/113; $59 \%)$. Nearly $1 / 3(37 / 113 ; 33 \%)$ were in academic practice, while $63 \%$ (71/113) were either in private or multispecialty practice. Nearly $1 / 4(23 \% ; 26 / 113)$ of the respondents reported performing more than 200 THAs or TKAs per year, while $41 \%(46 / 113)$ of respondents reported performing less than 100 per year.

\section{Statistical Analysis}

Each subject's responses for the experimental case (white female, black male, or black female) were paired with their responses for the control case (white male). The effect of race and sex on the primary outcome (willingness to recommend TKA) was analyzed using McNemar's test for matched pairs. The "probably" and "definitely" responses were combined to create a single dichotomous outcome (recommend or not recommend). Potential associations between physician characteristics (years in practice or annual volume) and perceived patient behaviors were evaluated using Spearman's correlation analysis.

An a priori power analysis showed that 112 participants were needed to detect a $15 \%$ difference in the likelihood of recommending surgery for white versus nonwhite patients

Table 1. Demographic information of respondents by case assignments

\begin{tabular}{|c|c|c|c|}
\hline Variable & $\begin{array}{l}\text { White male }+ \\
\text { black female } \\
(\mathrm{n}=39)\end{array}$ & $\begin{array}{l}\text { White male }+ \\
\text { black male } \\
(\mathrm{n}=37)\end{array}$ & $\begin{array}{l}\text { White male }+ \\
\text { white female } \\
(\mathrm{n}=37)\end{array}$ \\
\hline Age (mean \pm SD) & $48.1 \pm 10.4$ & $51.4 \pm 9.8$ & $51.9 \pm 11.3$ \\
\hline Sex (number/\% male) & $35(90 \%)$ & $36(97 \%)$ & $36(97 \%)$ \\
\hline Ethnicity (number/\% Caucasian) & $30(77 \%)$ & $34(92 \%)$ & $32(86 \%)$ \\
\hline \multicolumn{4}{|l|}{ Years in practice } \\
\hline$\leq 10($ number/\% $)$ & $15(38 \%)$ & $9(24 \%)$ & $10(27 \%)$ \\
\hline$>10($ number $/ \%)$ & $24(62 \%)$ & $28(76 \%)$ & $27(73 \%)$ \\
\hline Board certification (number/\% yes) & $36(92 \%)$ & $36(97 \%)$ & $35(95 \%)$ \\
\hline \multicolumn{4}{|l|}{ Practice setting } \\
\hline Academic (number/\%) & $15(38 \%)$ & $12(32 \%)$ & $10(27 \%)$ \\
\hline Private or multispecialty (number/\%) & $22(56 \%)$ & $25(68 \%)$ & $24(65 \%)$ \\
\hline Other (number/\%) & $2(5 \%)$ & 0 & $3(8 \%)$ \\
\hline Arthroplasty fellowship (number/\% yes) & $23(59 \%)$ & $23(62 \%)$ & $21(57 \%)$ \\
\hline \multicolumn{4}{|l|}{ Annual THA/TKA volume } \\
\hline$\leq 100($ number/\% $)$ & $14(36 \%)$ & $16(43 \%)$ & $16(43 \%)$ \\
\hline 100-200 (number/\%) & $18(46 \%)$ & $11(30 \%)$ & $12(32 \%)$ \\
\hline$>200($ number/\%) & $7(18 \%)$ & $10(27 \%)$ & $9(24 \%)$ \\
\hline
\end{tabular}


in the test scenarios evaluated with $90 \%$ power at a level of significance of 0.05 .

\section{Results}

\section{Association of Race with Recommendation for TKA}

With the numbers available, there was no association between the race of the patient in the test scenario and the surgeon making a recommendation in favor of surgery ( $\mathrm{p}=0.99$ in the black female and white male case pairing; $\mathrm{p}=0.32$ in the black male and white male case pairing). Of the 39 respondents who viewed the black female and white male case pairing, $15 \%$ (six of 39) of the responses were discordant (surgery recommended for one patient, but not the other) (Table 2). Of the 37 respondents who viewed the black male and white male case pairing, $11 \%$ (four of 47) of the responses were discordant (Table 2).

\section{Association of Sex with Recommendation for TKA}

With the numbers available, there was no association between the sex of the patient in the test scenario and the surgeon making a recommendation in favor of surgery $(\mathrm{p}=0.71)$. Of the 37 respondents who viewed the white female and white male case pairing, 24 (65\%) recommended TKA for both and six (16\%) did not recommend TKA for either. Four (11\%) respondents recommended TKA for the white male, but not the white female. Three (8\%) respondents did not recommend TKA for the white male, but recommended TKA for the white female. The effect of sex in this case was not statistically significant (Table 2).

\section{Discussion}

A total joint arthroplasty is a widely used intervention for advanced arthritis, but there is substantial concern that certain minority groups and women are less likely to receive a recommendation for surgery, even when clinically indicated [4, 5, 8, 14, 20, 37]. Previous studies have suggested that physician-related factors may contribute to differential use of total joint arthroplasties among women and ethnic minorities [5, 35]. We therefore sought to determine whether race and sex influenced surgeon recommendations for TKA in a simulated clinical setting. When presented with "prosurgery" clinical video scenarios of patients with longstanding pain and functional limitation from severe knee arthritis which had failed the standard course of nonoperative interventions, orthopaedic surgeons were not influenced by patient race or sex in their recommendations for TKA.

There are potential limitations to our study. Previous qualitative research has shown the importance of communication between patient and surgeon in the decisionmaking process for total joint arthroplasties [15]. Our videos may not have adequately captured the complexities and depths of the patient that inform the patient-physician interaction. Psychosocial factors such as fear, religious beliefs, and social network experiences provide a significant influence in the decision making of African-American and Hispanic patients referred for hip or knee arthroplasty and may play a role as patient factors responsible for underuse of joint replacement in minority populations [27, 31]. Our study does not consider the influence of these patient factors. There also was no opportunity for the respondent to further assess characteristics that may influence decisions to recommend TKA, such as health literacy [23], ability to participate in care [10], social support [41], and resource availability attributable to geographic constraints [37]. The informed and health-literate appearance of the patients in the videos may have directed respondents toward recommending TKA, as presentation style and perception of willingness to undergo surgery are critically influential factors that affect recommendations for total joint arthroplasties [18]. However, case vignettes can provide valid information regarding actual physician behavior [32] and have been used in a similar investigation [36]. Using vignettes permitted us to experimentally evaluate the influence of patient race and sex on decision-making among a large group of surgeons. Furthermore, we anecdotally

Table 2. Recommendations for TKA according to case assignment

\begin{tabular}{|c|c|c|c|c|c|c|}
\hline \multirow[t]{2}{*}{ Case } & \multicolumn{2}{|c|}{ Black female } & \multicolumn{2}{|c|}{ Black male } & \multicolumn{2}{|c|}{ White female } \\
\hline & Yes & No & Yes & No & Yes & No \\
\hline \multicolumn{7}{|c|}{ White male } \\
\hline Yes & 31 & 3 & 33 & 1 & 24 & 4 \\
\hline \multirow[t]{3}{*}{ No } & 3 & 2 & 3 & 0 & 3 & 6 \\
\hline & \multicolumn{2}{|c|}{ Concordant 33/39 (85\%) } & \multicolumn{2}{|c|}{ Concordant 33/37 (89\%) } & \multicolumn{2}{|c|}{ Concordant 30/37 (81\%) } \\
\hline & \multicolumn{2}{|c|}{ Discordant $6 / 39(15 \%)$} & \multicolumn{2}{|c|}{ Discordant 4/37 (11\%) } & \multicolumn{2}{|c|}{ Discordant 7/37 (19\%) } \\
\hline
\end{tabular}


noted that many respondents indicated that they would have preferred to have more information about the patients. This finding suggests that other factors contribute to surgeon decision-making, but were not captured by our vignettes. One example of this type of information is the absence of a plain radiograph in the survey presentation. We deliberately chose not to include a radiograph in the vignette to minimize any undue influence of imaging in cases already indicated for TKA on a clinical basis. Additionally, the respondent sample includes only surgeons who attended the selected meetings and agreed to participate in the survey. This limits the generalizability of these findings outside these groups. Surgeons attending subspecialty meetings such as the AAHKS may have different thresholds for which to offer a TKA compared with a general orthopaedic surgeon, such as those attending the NYSSOS meeting. Further, the vignettes we chose may have been overly clear from a clinical perspective as to eliminate the ability to measure implicit bias. The vignettes were deliberately created as "prosurgery", with the intent to steer the respondent toward recommending TKA. Vignettes in which the surgical indication was less clear may have yielded different results. Additionally, social desirability bias and response bias may have influenced the answers provided by the participants [11]. Subjects may have been familiar with the increasing attention directed toward elimination of healthcare disparities, which may have affected their responses. Furthermore, while we performed an a priori power analysis to determine the number of subjects needed to detect a $15 \%$ difference in recommendations for TKA, it is possible that smaller differences in recommendations may have gone undetected (Type II error). Finally, it is possible that patient race and sex may have differentially influenced decision making for each respondent. Using our current method of comparing with a baseline scenario for a white male, we are unable to evaluate the independent influence of race or sex, but are able to evaluate them together as a single characteristic (as was analyzed in the black female versus white male scenario). Despite these limitations, we believe our study contributes to the ongoing investigation of the circumstances surrounding disparities in the use of total joint arthroplasties.

Our findings regarding sex can be viewed in the context of the study from Borkhoff et al. [4]. In their investigation, standardized patients with moderate knee arthritis visited 33 orthopaedic surgeons in practice in Toronto, Canada. Orthopaedic surgeons were more likely to recommend TKA to a male patient rather than a female patient, which did not occur in our experiment. While the methods used by Borkhoff et al. are more likely to solicit behavior that replicates clinical practice, our investigation was able to draw from a larger sample of surgeons from various practice types. Additional investigation is needed to explore the influence of patient sex on recommendations for total joint arthroplasties because of the differences in practice environments and insurance coverage between the United States and Canada.

Although no prior experimental studies have evaluated the effect of patient race on surgeon recommendations for total joint arthroplasties, our findings support the notion that patient race and sex may be less influential on decision making when strong clinical data exist to support a decision. The robust clinical rationale presented in the video vignettes may have driven the respondents toward recommending TKA [30]. In several independent observational studies, clinical appropriateness, not patient race, was predictive of referral to an orthopaedic surgeon for possible total joint arthroplasty or for surgeon recommendation of total joint arthroplasty [3, 18, 38]. Our cases intentionally depicted patients who would benefit from TKA, as all had nonoperative treatment that failed and had symptoms preventing a desired level of function. The appropriateness of these patients for surgery is supported by the literature [7] and was confirmed with an a priori internal review of the vignettes by arthroplasty surgeons not involved in the investigation. Our findings corroborate vignette-based studies for bariatric surgery [34] and high-risk obstetric referral [33] that showed no effect of race on decision making when strongly supportive clinical data are present. However, this does not exclude physician bias from being a potential contributor to the existing disparities in the use of TKAs, particularly given its influence on treatment recommendations for other conditions [12, 25, 36]. The effect of unconscious bias on decision making may be stronger in cases where clinical decisions are not firmly supported, the so-called "gray area" $[33,35]$. Considering that a study arm of standardized patients with severe knee arthritis was aborted in the study by Borkhoff et al. owing to futility, their patients with moderate knee arthritis may have been in the gray area and therefore better positioned to solicit the effect of physician bias [4]. The factors that drive decision making in the gray area deserve future investigation given that efforts to reduce disparities in use of total joint arthroplasties are not succeeding [23, 24]. However, our findings indicate that physician bias does not influence arthroplasty recommendations in vignettes with clear support for surgical intervention. This is particularly salient as use of total joint arthroplasties is projected to increase dramatically [26] and the integration of appropriate use criteria is being encouraged $[13,19]$.

Continued investigation into the biases and practices of orthopaedic surgeons will contribute to greater understanding of disparities in the use of total joint arthroplasties. With the numbers available, we did not detect a difference in recommendations by surgeons for TKA in a clearly indicated scenario based on patient race and sex. With this in mind, future studies should explore 
the influence of physician bias on decision making in situations when indications for surgical treatment are less clear.

Acknowledgments We thank Kara Fields MPH (Hospital for Special Surgery; New York, NY) for contributions to the statistical analysis; Diana Santanello BS (Hospital for Special Surgery; New York, NY) for assistance in survey administration; and the leadership of the American Association of Hip and Knee Surgeons and the New York State Society of Orthopaedic Surgeons for allowing subject recruitment and enrollment at their annual meetings.

\section{References}

1. Amaranto DJ, Abbas F, Krantz S, Pearce WH, Wang E, Kibbe MR. An evaluation of gender and racial disparity in the decision to treat surgically arterial disease. J Vasc Surg. 2009;50:1340-1347.

2. American Academy of Orthopaedic Surgeons Department of Research and Scientific Affairs. Orthopaedic Practice in the U.S. 2012. Available at: http://www.aaos.org/research/orthocensus/ census.asp. Accessed April 25, 2013.

3. Ang DC, James G, Stump TE. Clinical appropriateness and not race predicted referral for joint arthroplasty. Arthritis Rheum. 2009;61:1677-1685.

4. Borkhoff CM, Hawker GA, Kreder HJ, Glazier RH, Mahomed NN, Wright JG. The effect of patients' sex on physicians' recommendations for total knee arthroplasty. CMAJ. 2008;178: 681-687.

5. Borkhoff CM, Hawker GA, Wright JG. Patient gender affects the referral and recommendation for total joint arthroplasty. Clin Orthop Relat Res. 2011;469:1829-1837.

6. Centers for Disease Control and Prevention. Healthy People 2010: Arthritis, Osteoporosis, and Chronic Back Conditions. Available at: http://www.cdc.gov/nchs/data/hpdata2010/hp2010_ final_review_focus_area_02.pdf. Accessed April 252013.

7. Cross WW 3rd, Saleh KJ, Wilt TJ, Kane RL. Agreement about indications for total knee arthroplasty. Clin Orthop Relat Res. 2006; 446:34-39.

8. Escalante A, Barrett J, del Rincon I, Cornell JE, Phillips CB, Katz JN. Disparity in total hip replacement affecting Hispanic Medicare beneficiaries. Med Care. 2002;40:451-460.

9. Figaro MK, Russo PW, Allegrante JP. Preferences for arthritis care among urban African Americans: "I don't want to be cut". Health Psychol. 2004;23:324-329.

10. Fraenkel L, Rabidou N, Wittink D, Fried T. Improving informed decision-making for patients with knee pain. J Rheumatol. 2007; 34:1894-1898.

11. Furnham A. The social desirability of the type A behaviour pattern. Psychol Med. 1986;16:805-811.

12. Furth SL, Hwang W, Neu AM, Fivush BA, Powe NR. Effects of patient compliance, parental education and race on nephrologists' recommendations for kidney transplantation in children. Am J Transplant. 2003;3:28-34.

13. Ghomrawi HM, Schackman BR, Mushlin AI. Appropriateness criteria and elective procedures: total joint arthroplasty. $N$ Engl J Med. 2012;367:2467-2469.

14. Giacomini MK. Gender and ethnic differences in hospital-based procedure utilization in California. Arch Intern Med. 1996;156: $1217-1224$

15. Gooberman-Hill R, Sansom A, Sanders CM, Dieppe PA, Horwood J, Learmonth ID, Williams S, Donovan JL. Unstated factors in orthopaedic decision-making: a qualitative study. BMC Musculoskelet Disord. 2010;11:213.
16. Groeneveld PW, Kwoh CK, Mor MK, Appelt CJ, Geng M, Gutierrez JC, Wessel DS, Ibrahim SA. Racial differences in expectations of joint replacement surgery outcomes. Arthritis Rheum. 2008;59:730-737.

17. Hanchate AD, Zhang Y, Felson DT, Ash AS. Exploring the determinants of racial and ethnic disparities in total knee arthroplasty: health insurance, income, and assets. Med Care. 2008;46:481-488.

18. Hausmann LR, Mor M, Hanusa BH, Zickmund S, Cohen PZ, Grant R, Kresevic DM, Gordon HS, Ling BS, Kwoh CK, Ibrahim SA. The effect of patient race on total joint replacement recommendations and utilization in the orthopedic setting. J Gen Intern Med. 2010;25:982-988.

19. Hawker GA, Badley EM, Borkhoff CM, Croxford R, Davis AM, Dunn S, Gignac MA, Jaglal SB, Kreder HJ, Sale JE. Which patients are most likely to benefit from total joint arthroplasty? Arthritis Rheum. 2013;65:1243-1252.

20. Hawker GA, Wright JG, Coyte PC, Williams JI, Harvey B, Glazier R, Badley EM. Differences between men and women in the rate of use of hip and knee arthroplasty. $N$ Engl J Med. 2000;342:1016-1022.

21. Ibrahim SA, Siminoff LA, Burant CJ, Kwoh CK. Variation in perceptions of treatment and self-care practices in elderly with osteoarthritis: a comparison between African-American and white patients. Arthritis Rheum. 2001;45:340-345.

22. Ibrahim SA, Siminoff LA, Burant CJ, Kwoh CK. Understanding ethnic differences in the utilization of joint replacement for osteoarthritis: the role of patient-level factors. Med Care. 2002;40:(1 suppl):I44-51.

23. Irgit K, Nelson CL. Defining racial and ethnic disparities in THA and TKA. Clin Orthop Relat Res. 2011;469:1817-1823.

24. Jha AK, Fisher ES, Li Z, Orav EJ, Epstein AM. Racial trends in the use of major procedures among the elderly. $N$ Engl J Med. 2005;353:683-691.

25. Krupat E, Irish JT, Kasten LE, Freund KM, Burns RB, Moskowitz MA, McKinlay JB. Patient assertiveness and physician decision-making among older breast cancer patients. Soc Sci Med. 1999;49:449-457.

26. Kurtz S, Ong K, Lau E, Mowat F, Halpern M. Projections of primary and revision hip and knee arthroplasty in the United States from 2005 to 2030. J Bone Joint Surg Am. 2007;89:780-785.

27. Lavernia CJ, Alcerro JC, Rossi MD. Fear in arthroplasty surgery: the role of race. Clin Orthop Relat Res. 2010;468: 547-554.

28. Mahomed NN, Barrett J, Katz JN, Baron JA, Wright J, Losina E. Epidemiology of total knee replacement in the United States Medicare population. J Bone Joint Surg Am. 2005;87:1222-1228.

29. Mehrotra C, Remington PL, Naimi TS, Washington W, Miller R. Trends in total knee replacement surgeries and implications for public health, 1990-2000. Public Health Rep. 2005;120:278-282.

30. Mota RE, Tarricone R, Ciani O, Bridges JF, Drummond M. Determinants of demand for total hip and knee arthroplasty: a systematic literature review. BMC Health Serv Res. 2012;12:225.

31. Parks ML, Hebert-Beirne J, Rojas M, Tuzzio L, Nelson CL, Boutin-Foster C. A qualitative study of factors underlying decision making for joint replacement among African Americans and Latinos with osteoarthritis. J Long Term Eff Med Implants. 2014;24: 205-212.

32. Peabody JW, Luck J, Glassman P, Dresselhaus TR, Lee M. Comparison of vignettes, standardized patients, and chart abstraction: a prospective validation study of 3 methods for measuring quality. JAMA. 2000;283:1715-1722.

33. Richardson DK, Gabbe SG, Wind Y. Decision analysis of highrisk patient referral. Obstet Gynecol. 1984;63:496-501.

34. Santry HP, Lauderdale DS, Cagney KA, Rathouz PJ, Alverdy JC, Chin MH. Predictors of patient selection in bariatric surgery. Ann Surg. 2007;245:59-67. 
35. Santry HP, Wren SM. The role of unconscious bias in surgical safety and outcomes. Surg Clin North Am. 2012;92:137-151.

36. Schulman KA, Berlin JA, Harless W, Kerner JF, Sistrunk S, Gersh BJ, Dube R, Taleghani CK, Burke JE, Williams S, Eisenberg JM, Escarce JJ. The effect of race and sex on physicians' recommendations for cardiac catheterization. $N$ Engl $J$ Med. 1999;340:618-626.

37. Skinner J, Weinstein JN, Sporer SM, Wennberg JE. Racial, ethnic, and geographic disparities in rates of knee arthroplasty among medicare patients. N Engl J Med. 2003;349:1350-1359.

38. Suarez-Almazor ME, Souchek J, Kelly PA, O’Malley K, Byrne M, Richardson M, Pak C. Ethnic variation in knee replacement: patient preferences or uninformed disparity? Arch Intern Med. 2005;165:1117-1124.

39. Toronto Arthroplasty Research Group Writing Committee, Wright JG, Hawker GA, Hudak PL, Croxford R, Glazier RH,
Mahomed NN, Kreder HJ, Coyte PC. Variability in physician opinions about the indications for knee arthroplasty. J Arthroplasty. 2011;26:569-575.e1.

40. United States Bone and Joint Initiative. USBJI About the Initiative. Available at: http://www.usbji.org/about/?pg=mission.cfm. Accessed April 25, 2013.

41. Vina ER, Masi CM, Green SL, Utset TO. A study of racial/ethnic differences in treatment preferences among lupus patients. Rheumatology (Oxford). 2012;51:1697-1706.

42. Wright JG, Coyte P, Hawker G, Bombardier C, Cooke D, Heck D, Dittus R, Freund D. Variation in orthopedic surgeons' perceptions of the indications for and outcomes of knee replacement. CMAJ. 1995;152:687-697. 